Deconstructivist architecture \& collage. Transdisciplinary project strategies of Gehry, Libeskind y Eisenman

PALABRAS CLAVE - ARPUITECTURA - DECONSTRUCCIONES COLLAGE . ESTRATEGIAS PROYECTUALES COLLACE · ESTRATECIAS

KEYWORDS - ARCHITECTURE • DECONSTRUCTIONS . COUACE . PROIECT STRATEGIES - TRANSDISCIPUINARITY

\section{RESUMEN}

Reiteradamente se ha planteado que los proyectos deconstructivistas se desarrollan a partir de estrategias similares a las empleadas en el collage. donde fragmentar, superponer, maclar son los puntos de contactos entre disciplina arquitectónica y técnica artística. A partir de ese punto de confluencia se bifurcan dos líneas de trabajo diferentes. Una es desarrollada por Gehry o Libeskind, donde se identifican fragmentaciones y reagrupaciones a partir de maclar volúmenes heteróclitos. Otra es llevada a cabo por Eisenman quien, a partir de una serie de excavaciones arqueológicas ficticias reagrupa

fragmentos de historias o ruinas del lugar a intervenir, a través de capas cartográficas que se superponen y dialogan articuladamente para concebir la propuesta edilicia, especialmente en sus proyectos de la serie Ciudades de la arqueología ficticia. Son dos formas diferentes de incorporar los recursos del collage en la producción arquitectónica contemporánea, y con énfasis en la arquitectura deconstructivista.

\section{ABSTRACT}

It has been repeatedly argued that deconstructivist projects are developed from strategies similar to those used in collage, where fragmenting, superimposing, interlocks are the points of contact between architectural discipline and artistic technique. From that point of confluence, two different lines of work diverge. One is developed by Gehry or Libeskind, where fragmentations and regrouping are identified from interlock heteroclite volumes. Another is carried out by Eisenman who, from a series of fictitious archaeological excavations, regroups fragments of stories or ruins of the place to be intervened through cartographic layers that are superimposed and articulate to conceive the building, especially the projects of the series Cities of Artificial Excavation. They are two different ways of incorporating collage resources in contemporary architectural production, and with an emphasis on deconstructivist architecture.

\title{
Arquitectura deconstructivista \& collage. Estrategias proyectuales transdisciplinares de Gehry, Libeskind y Eisenman
}

\author{
VICENTE ESTEBAN MEDINA · Universidad Nacional de Tucumán·d31251@hotmail.com \\ Fecha de recepción: 12 de abril de 2021 - Fecha de aceptación: 31 de mayo de 2021
}

\section{INTRODUCCIÓN}

Las propuestas arquitectónicas deconstructivistas han sido etiquetadas con frecuencia como proyectos desarrollados a partir de estrategias proyectuales similares a las empleadas en el collage, donde fragmentar, superponer o maclar, parecen ser los puntos de contactos entre ambos planteamientos. A este asunto queremos atender en esta presentación. El artículo pretende demostrar en qué medida en collage ha constituido un referente clave en la conformación de las estrategias proyectuales deconstructivistas.

La relación histórica entre collage y arquitectura se pone de manifiesto en las producciones artísticas y arquitectónicas de las vanguardias de principios del siglo XX; cubismo, dadá, constructivismo, etc. Incluso, en la relación entre collage y fotomontaje utilizada como arte y arquitectura de acción, como señala Linares García, F. (2018), Ilegando a generar en algunos casos auténticas Real Fiction como plantea Lus Arana, L. (2017).

Se ha señalado con énfasis que numerosos arquitectos del siglo XX han recurrido al collage como fuente de inspiración en algunos de sus proyectos ${ }^{1}$. Le Corbusier, Lubetkin o Aalto son algunos de los nombres que aparecen en la obra de Santiago de Molina Collage y Arquitectura (de Molina, 2014), u otros referenciados en la Tesis doctoral de Fernando Freitas Fuao Arquitectura como collage (Freitas Fuao, 1992), investigaciones fundamentales sobre el asunto. Donde la conjunción copulativa cómo perspicazmente abre a la puerta a un sinnúmero de reflexiones en torno a dichas técnica pictórica y estrategia arquitectónica: señala las intenciones de algunas propuestas arquitectónicas de recurrir al collage como punto de referencia o inspiración en el proceso creativo, aprovechando también las metáforas que tal técnica artística dispara. Y algunos arquitectos deconstructivistas recurrieron a ello, como muestra Santiago de Molina en su obra, dedicando capítulos completos al trabajo de Gehry y Koolhaas.

Si bien podríamos confirmar que los siete estudios de arquitectura reunidos en el MoMA en 1988 y etiquetados como deconstructivistas evidencian referencias al collage en sus proyectos, hay dos líneas bien definidas a las que queremos atender, dada sus formas de reutilizar las estrategias del collage: una se refleja en el trabajo de Gehry y Libeskind, la otra en la de Eisenman. A los primeros los podríamos vincular a un collage tectónico 
mientras que a Eisenman podemos relacionarlo con lo que de Molina ha denominado collage intelectual. Las exacerbadas fragmentaciones y recomposiciones volumétricas macladas de las estrategias de Gehry y Libeskind contrastan con las planimetrías o cartografías históricas propuestas de Eisenman; son dos resultantes diferentes a partir de la misma técnica del collage. Los primeros fragmentan, superponen y maclan volúmenes. Eisenman escoge estratos de la memoria del lugar, fragmentos abstractos de ruinas e historias sedimentadas en el sitio que relaciona a través de múltiples capas. Gehry organiza sus proyectos articulando volúmenes heteróclitos generando una dialéctica entre lo ordenado y lo caótico, entre los apolíneo y lo dionisíaco, acción que enfatiza con el acabado superficial de los mismos. Eisenman compone sus collages proyectuales con ruinas y restos del pasado, realizando injertos históricos intelectualizados; cataliza las técnicas del collage en estrategias abonadas teóricamente con los discursos filosóficos a los que está relacionado y también con planteamientos heredados de Colin Rowe.

\section{GEHRY, LIBESKIND \& LA ARQUITECTURA DEL FRAGMENTO, LA MACLA Y LO HETERÓCLITO}

Los proyectos arquitectónicos contemporáneos basados en la fragmentación son numerosos y variados, al igual que las argumentaciones que las fundamentan. Javier Maderuelo, por ejemplo, en El espacio raptado señala que la "oblicuidad de la arquitectura" y el "fenómeno de la pérdida del centro" son causas importantes "de la fragmentación de las obras y la pérdida del carácter unitario de las mismas, dando paso a una serie de objetos constituidos por elementos aparentemente irreconciliables" (Maderuelo, 1990, p. 311 1). También plantea que, tras la fragmentación, la obra se recompone con una nueva estructura, "la cual cobra un carácter articulatorio que recuerda formalmente el collage" (Maderuelo, 1990, p. 311 1). Efectivamente, la fragmentación ha abolido los criterios de composición basados en
1. Fragmentación en proyectos deconstructivas. Elaboración propia, 2021. [Las imágenes fueron editadas por el autor del texto y el seminarista Facundo Saúl Alberto, en el marco de las actividades desarrolladas en el I Seminario de Arquitectura Reciente y Actual - SARA I dirigido por el Prof. Medina en la Facultad de Arquitectura y Urbanismo de la Universidad Nacional de Tucumán (Res. 048-2018: HCD-FAU-UNT). Los dibujos insertos en las imágenes fueron realizados por el autor del texto].

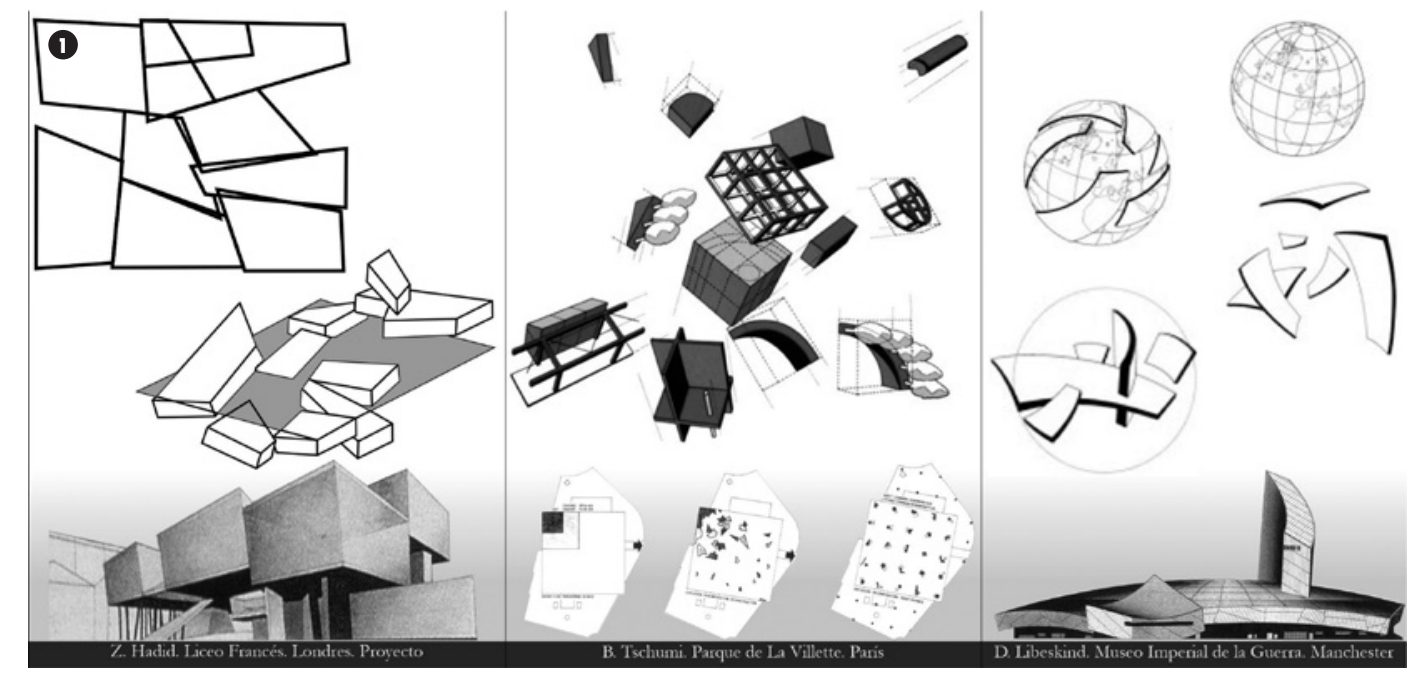

la centralidad, ejes únicos, simetría, contorno definido, etc., como demuestran la multiplicidad de centralidades o de ejes presentes en las plantas de los proyectos deconstructivistas, y donde el contorno claro es reemplazado por un límite formal indeterminado, impreciso. Alineándonos con el planteamiento de Madervelo, la idea de una arquitectura basada "en el fragmento y en el collage, tiene su origen en un nuevo afán por el análisis de lo particular, de la disección de elementos descontextualizados, de los que interesa más descubrir sus particularidades y diferencias". Pero a su vez, estas singularidades "tras su descomposición analítica, se vuelve a reunir y reinterpretar desde un punto de vista que no le permite reaparecer bajo su forma original, sino transformada en un nuevo objeto que enseña desvergonzadamente su contenido". Como sugiere Juan Antonio Ramírez, éstas obras "no se reconstruye con la mirada, sino también con la actividad compleja de la mente" (Maderuelo, 1990, p. 31 1). Lo expuesto se verifica en proyectos como el de Zaha Hadid para el Liceo Francés en Londres desarrollado a partir de un esquema fragmentado, el de Daniel Libeskind en el cual despedaza la corteza terrestre para proyectar el Museo Imperial Guerra, o el de Bernard Tschumi para el Parque de La Villette, a partir del fraccionamiento del programa de actividades y de las folies. Proyectos que además tienen unas curiosas similitudes gráficas en sus presentaciones (FIGURA 1).

En relación a lo expuesto Tschumi (1988) plantea lo siguiente:

\begin{abstract}
.. la arquitectura solo existe a través del mundo en que se ubica. Si este mundo implica disociaciones y destruye la unidad, la arquitectura lo reflejará inevitablemente (...) La fragmentación de nuestra loca situación contemporánea sugiere inevitablemente reagrupamientos nuevos e imprevistos de sus fragmentos (...) Estos fragmentos autónomos pueden ser recombinados a través de una serie de permutaciones (p. 25, 32).
\end{abstract}

Consecuente con su discurso, en su proyecto para el Parque de La Villette, Tschumi fracciona el programa en tres grupos de actividades, con los cuales genera tres capas diferentes. Un estrato alberga los grandes espacios destinados a zonas verdes, campos de juego y conciertos al aire libre, como así también, los edificios de cine, museo de ciencias, auditorio, etc. Otra capa contiene las circulaciones y paseos. Y la tercera se estructura a partir de una retícula en cuyas intersecciones ubicó las folies: unos fragmentados cubos rojos (FIgUra 2). Como sostiene Lucan "fragmentar, combinar y 
2. Bernard Tschumi. Parque de La Villette. Elaboración propia, 2021.

3. Zaha Hadid. Hotel/Torre Calle 42 \& Peter Eisenman. Casa X. Elaboración propia, 2021.
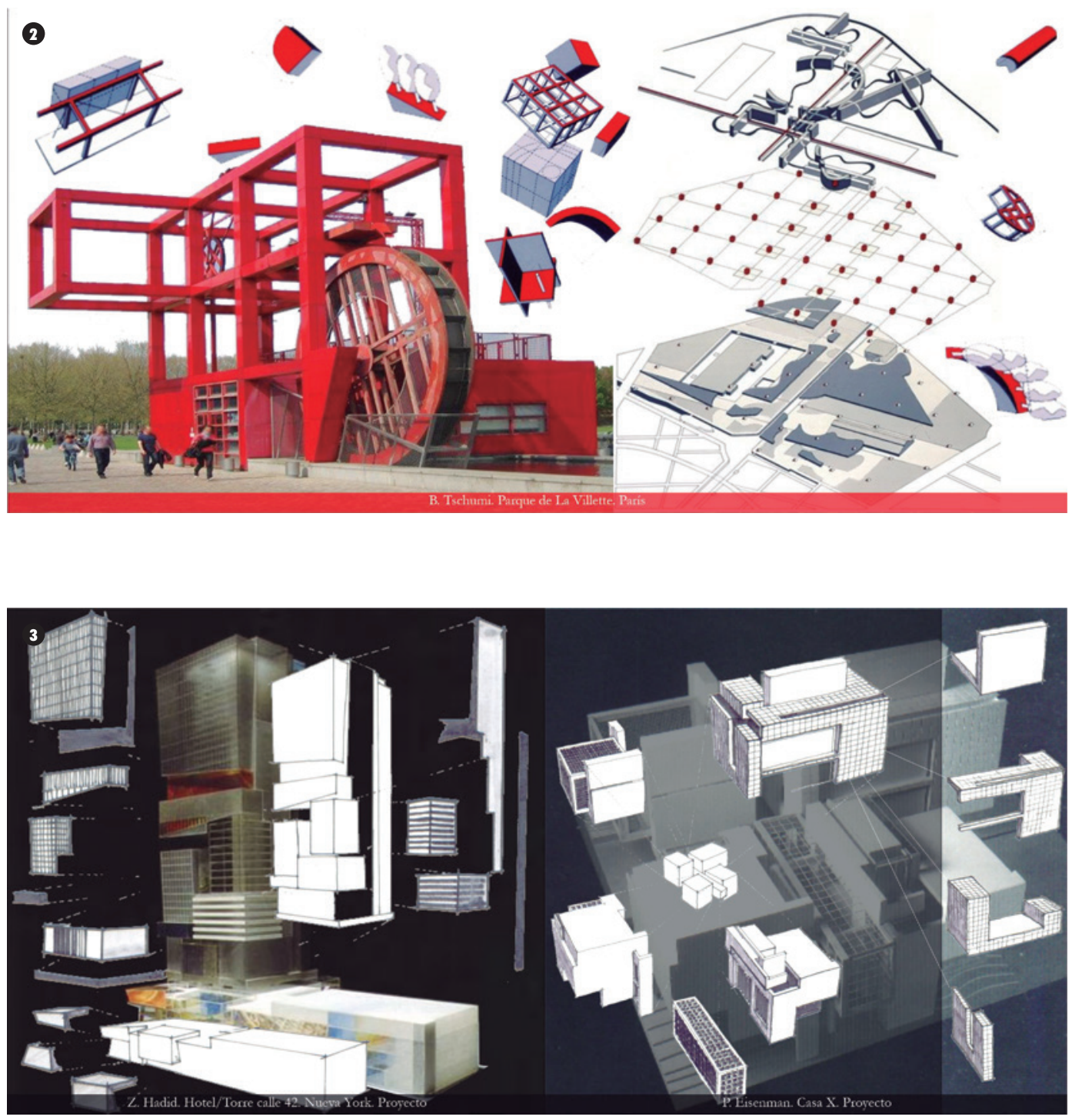

superponer" es la clave de este proyecto (Lucan, 1988, p. 22).

Al igual que Tschumi otros arquitectos recurren a esta estrategia. Hadid en su proyecto para el Hotel/Torre de la Calle 42 de Nueva York fragmenta el conjunto en basamento y torre; ésta a su vez en semitorres, a las cuales asigna tratamientos superficiales diferenciados para acentuar la fragmentación (Figura 3). Peter Eisenman hace un gran uso de éste recurso en las Cardboard Houses ${ }^{2}$. Sin embargo, donde éste alcanza un punto álgido y con múltiples direcciones es en su proyecto para la Casa $X$ (FIgURA 3). Si bien las L-Form son los elementos morfológicos fundantes del proyecto, Eisenman fracciona el programa de la vivienda en cuatro áreas, cuyas volumetrías fragmenta en sus

planos constitutivos, dando a cada uno de éstos diferentes tratamientos superficiales, a partir de módulos y submódulos del cubo inicial.

Sin embargo, quien utiliza la fragmentación con mayor frecuencia es Frank Gehry. Paradójicamente, al respecto comenta: "nunca he entendido por qué los críticos han calificado mi trabajo como fragmentario" (Zaera-Polo, 1995, p. 24). No obstante, reconoce que quizás en la Casa Norton, estas ideas de fragmentación y relaciones urbanas alcanzaron su máxima expresión, tomando prestados trozos del paisaje urbano, formas y materiales para establecer relaciones (visuales) con la ciudad (Zaera-Polo, 1995, p. 27).

En los laboratorios de la Universidad de lowa Gehry fragmenta el programa en cinco sectores de clara volumetría. Los laboratorios de investigación y asistencia se organizan en dos bloques lineales y regulares revestidos en cobre y piedra caliza respectivamente. A éste último se adosa un tercer elemento lineal que sirve, formal y visualmente, de transición entre los bloques de laboratorios y el conjunto de volúmenes solapados desordenadamente que albergan los despachos, puesto que tiene la regularidad del primero y el revestimiento de los segundos. El quinto elemento lo constituye una pieza exenta destinada a la sala de conferencias (FIGURA 4).

En la Residencia Schnabel Gehry fracciona la vivienda en ocho áreas, estas en sectores y estos en zonas que se materializan en diversos volúmenes. Por sus características formales, las áreas se reúnen en dos grupos: una con cuerpos dislocados dispuestos heteróclitamente y otra con elementos ortogonalmente reunidos. La obra evidencia un exhaustivo fraccionamiento funcional y volumétrico que reverbera en el lucernario ubicado sobre el dormitorio principal, el cual despieza enfáticamente sus elementos estructurales (FIgURA 4).

En las oficinas Vitra de Basilea el conjunto se articula en dos áreas bien diferenciadas: las oficinas que se alojan en un pabellón lineal, y los accesos y servicios que se reúnen en un

\footnotetext{
Cardboard Houses (Casas de cartón) se denominan las primeras viviendas diseñadas por Eisenman.
} 
edificio de volúmenes topológicos, donde cada función -el hall de acceso, las salas de exposiciones, de reuniones, el bar, etc.- tiene asignada una forma, un material y hasta un color diferente (FIGURA 5).

En el Centro de Comunicación y Tecnología EMR de Bad Oeynhausen el programa de necesidades se divide en cinco áreas donde cada una tiene su propia identidad. Cada área, funcionalmente diferentes, tienen formas dispares, independiente, amorfas, asimétricas y desiguales (FIGURA 5).

Libeskind también recurre a la fragmentación como parte de sus estrategias proyectuales, pero con una mayor regularidad volumétrica de fragmentos. Desde el fraccionamiento gráfico del Maguén David o Sello de Salomón para diseñar la planta del Museo Judío de Berlín hasta los trozos que se articulan para configurar los proyectos del Museo Felix Nussbaum o la Filarmónica de Bremen, todos son geométricamente más regulares y ordenados entre sí, que los propuestos por Gehry (Figura 6).

En algunos proyectos de Gehry, el uso de este recurso repercute en los revestimientos superficiales que fragmenta en módulos, y acentúa colocándolos desfasados a modo de escamas, sin distinción del material, sea piedra, acero, o cristal, un lenguaje que hereda de sus diseños de mobiliarios con formas de peces o serpientes. Incluso en otros casos la fragmentación llega a niveles que emulan de desintegración material del edificio. Por ejemplo, en el Centro Cultural y Comercial Edgemar Gehry lleva la fragmentación a tal punto que algunos volúmenes muestran sólo sus elementos estructurales y en casos extremos se manifiestan únicamente a través de sus aristas, como también observamos en algunas folies de Tschumi.

Frente a estas propuestas arquitectónicas, son numerosas las inquietudes e interrogantes que surgen. Rafael Moneo hace un importante aporte teórico al respecto al plantear que "Gehry
4. Frank Gehry. Laboratorios de la Universidad de lowa \& Residencia Schnabel. Elaboración propia, 2021.

5. Frank Gehry. Oficinas Vitra \& Centro de Comunicación y Tecnología EMR. Elaboración propia, 2021.

6. Daniel Libeskind, Filarmónica de Bremen \& Museo Felix Nussbaum. Elaboración propia, 2021.
(4)

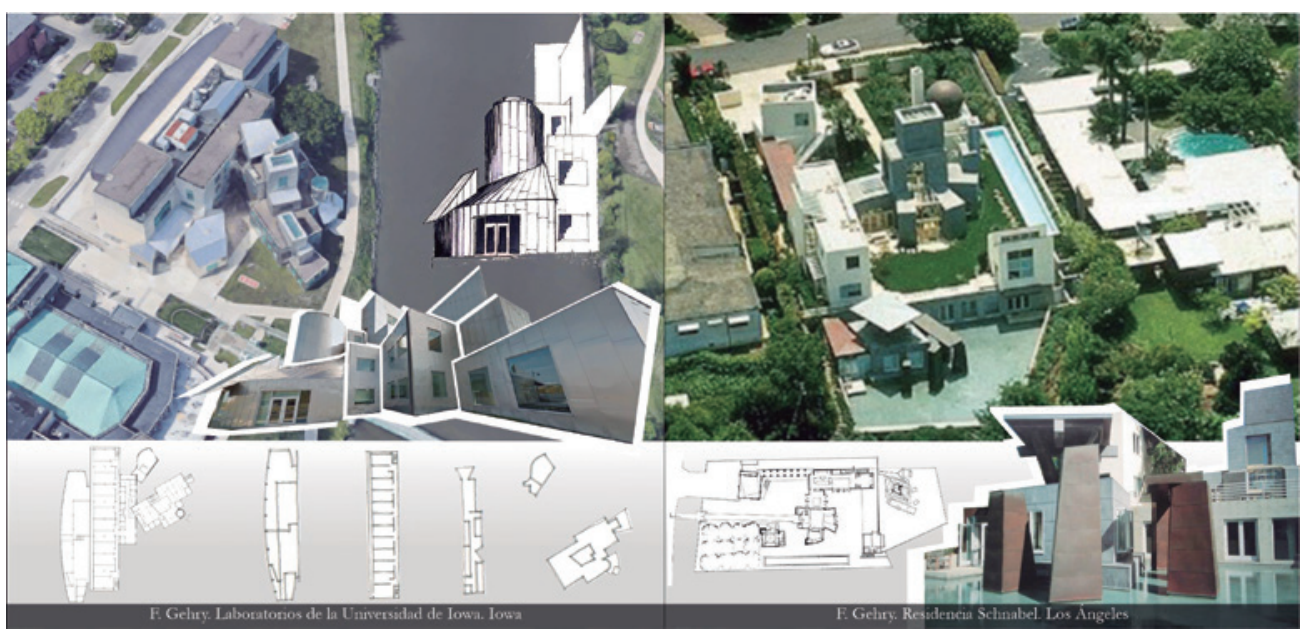

5

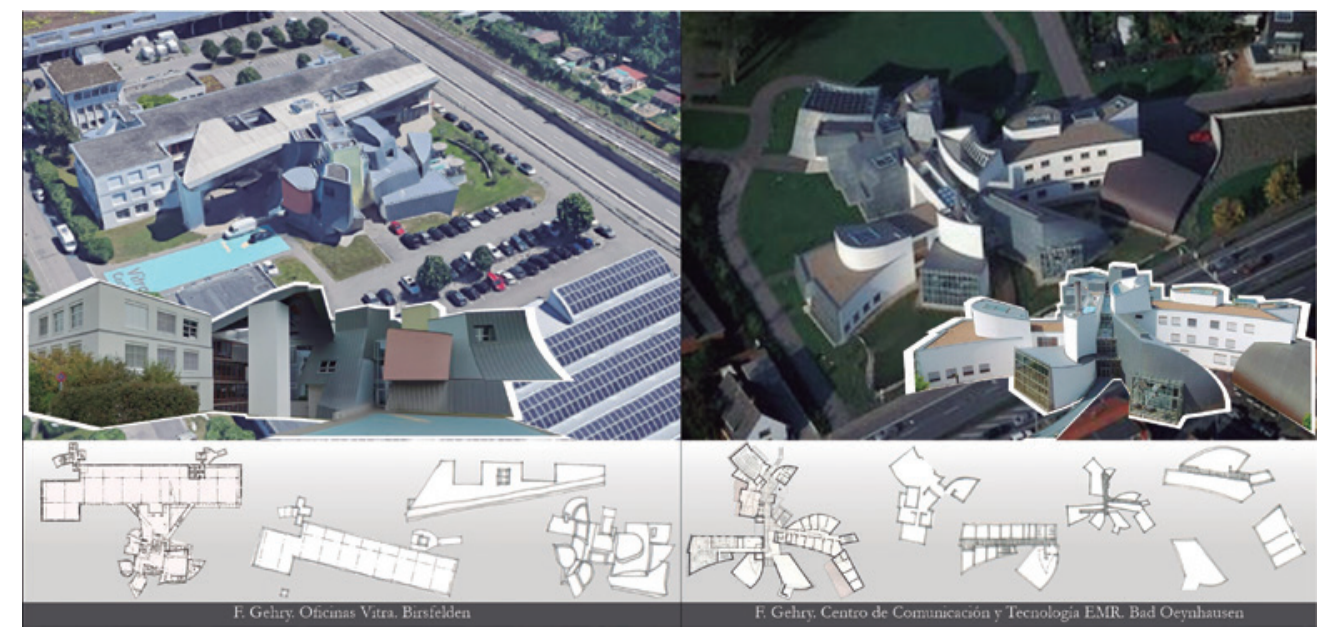

6

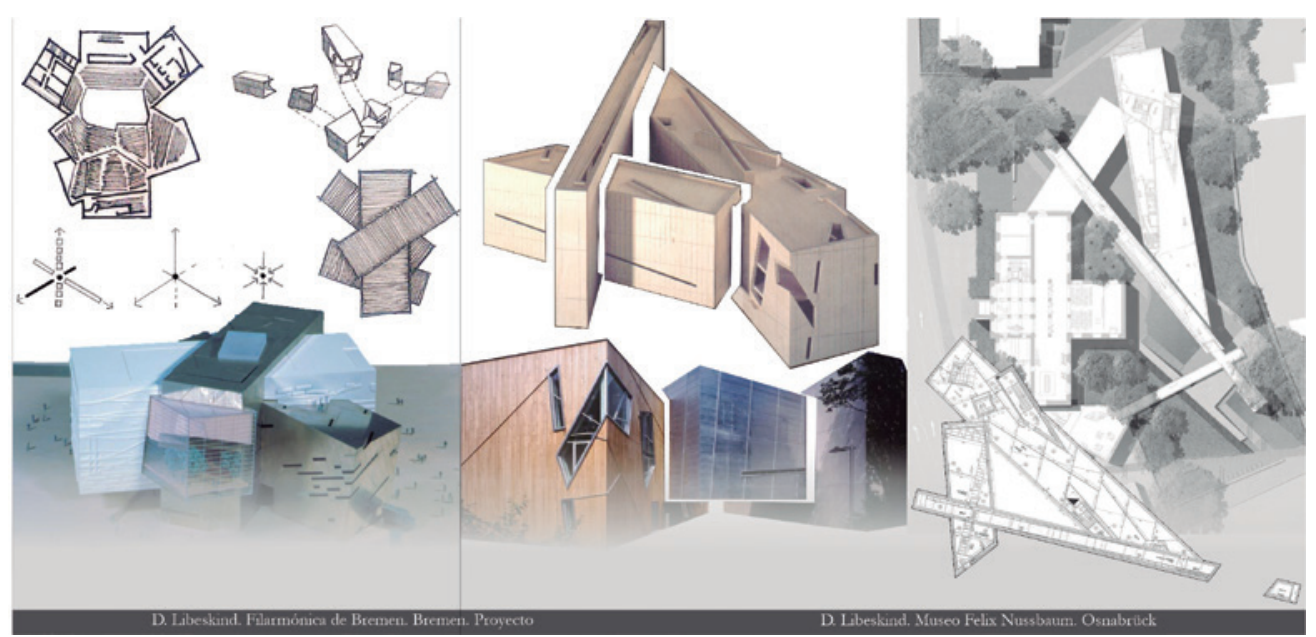


no comienza su trabajo considerando tipos conocidos. Gusta de examinar atentamente el programa para poder, más tarde, desmembrarlo. Tal desmembramiento le permitirá asignar formas a las distintas funciones. El repertorio de tales formas es elemental. Gehry las conoce bien" (Moneo, 1990, p. 9). En un sentido más general, Francisco de Gracia en Construir en lo construido postula el "experimentalismo arquitectónico sin soporte metodológico" como causa de la fragmentación, destacando "la autonomía de los elementos y la voluntad de invención por acumulación de formas ingeniosas" 3 (de Gracia, 1996, p. 306). Un experimentalismo que emula las técnicas de fragmentación utilizadas en el collage. También hay quienes sostienen que este recurso es reflejo de la fragmentación urbana: Colin Rowe, en Ciudad Collage, plantea que la ciudad es una unidad fragmentada, cuyas fracciones están superpuestas a modo de collage (Rowe, Koetter, 1981).

Pero estos fragmentos no permanecen sueltos en el proyecto. O sí, en ocasiones. Como sugiere Moneo respecto al trabajo de Gehry, "El siguiente paso será el dar una estructura común a todas estas formas primarias elementales. Cada pieza, cada elemento, conservará su integridad formal y el edificio puede entenderse como la representación de un campo de fuerzas" (Moneo, 1990, p. 9). En el caso de Gehry las piezas se reúnen o articulan mediante una estratégica herramienta heredada de la mineralogía, la macla, que en dicha disciplina designa un conjunto formado por dos o más cristales que se han vinculado a través de la penetración.

Federico Soriano se refiere a la macla como "una colisión entre piezas como medio de producir tensión" (Soriano, 1996, p. 8). Francis Ching, en su estudio sobre las formas aditivas, explica que los volúmenes maclados se caracterizan porque "cada forma penetra en el

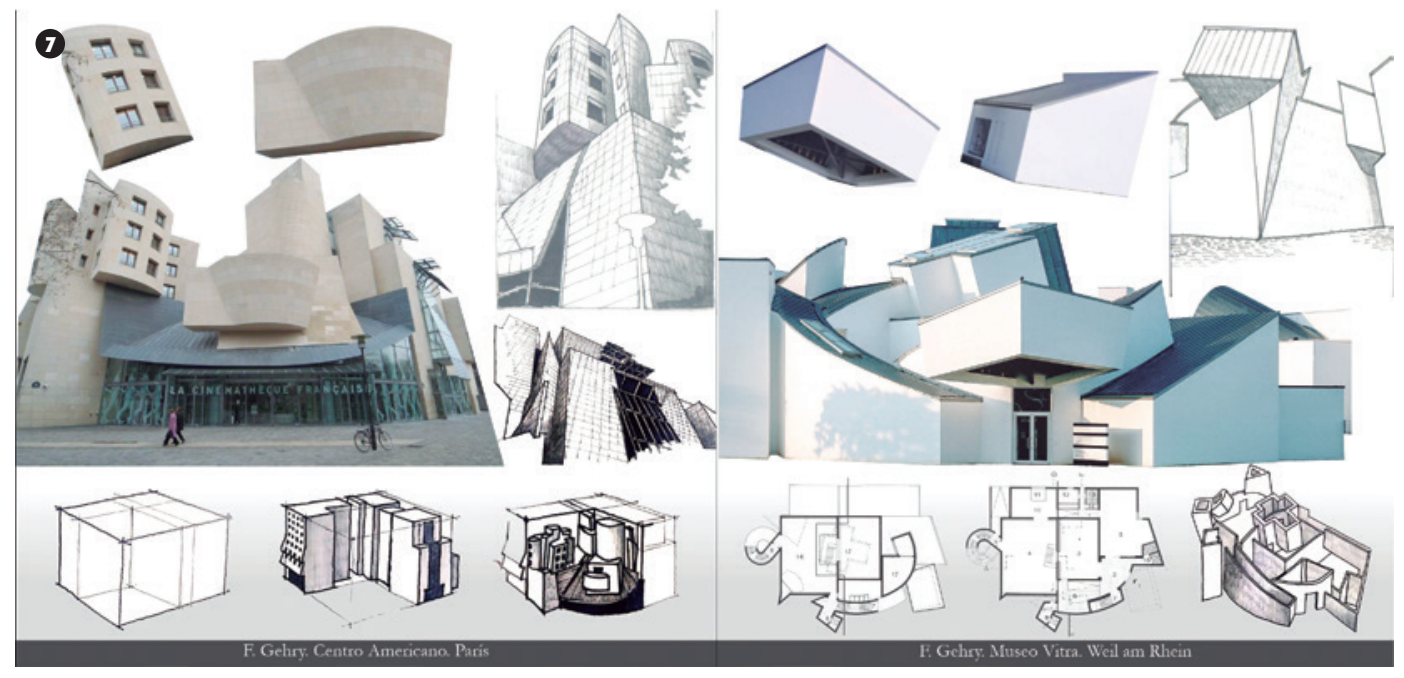

espacio de la otra" y porque son "formas que no precisan compartir un rasgo visual alguno" (Ching, 1998, p. 56). Las maclas otorgan a los edificios deconstructivistas su carácter heteróclito y facilitan la articulación de los fragmentos que componen el conjunto, permitiéndoles mantener su independencia formal; es lo que observamos en los trabajos de Gehry y Libeskind antes mencionados. Sin embargo, Libeskind, a diferencia de Gehry, compone maclas más regulares y con una menor participación de elementos, como vemos en el Museo Nussbaum o en la Filarmónica de Bremen, en donde compenetra pocos prismas, dispuestos cartesiana y anticartesianamente.

El carácter heteróclito de las maclas y la independencia formal de sus elementos se intensifican a través de los tratamientos superficiales otorgado a los fragmentos por medio de la combinación de diversos materiales: metales, maderas, piedras, etc. Esto se produce marcadamente en las obras de Gehry. Y también en algunas de Libeskind. Volúmenes revestidos en metal se articulan con otros vidriados, que a su vez dialogan con otros revestidos en madera u hormigón.

\footnotetext{
El autor (de Gracia, 1996, p. 306) utiliza una cita de Manfredo Tafuri. (1997, p. 144).
}

Pero como toda regla tiene su excepción, ésta la encontramos en algunas obras de Gehry. En el Centro Americano de París y en el Museo Vitra los fragmentos maclados se revisten con un único material: aplacado de piedra en el primero, y un inmaculado estucado blanco en el segundo. Estas propuestas constituyen anomalías en su trayectoria proyectual, caracterizada por enfatizar la diferenciación de volúmenes, a través diversos revestimientos (FIGURA 7).

Fragmentación y macla constituyen recursos proyectuales que emparentan algunas producciones arquitectónicas con las realizadas en la técnica del collage; éste constituye para Gehry y Libeskind un referente instrumental de producción morfológica. En cambio, otros arquitectos lo emplean como un recurso para abonar su pensamiento y la representación gráfica de sus proyectos, como ocurre en algunos de proyectos de Eisenman.

\section{EISENMAN \& LA ARQUITECTURA DEL LAYER, LAS SUPERPOSICIONES Y LAS METÁFORAS}

Si en el caso de Gehry la reunión o articulación de los fragmentos se lleva a cabo mediante la macla, en el caso de Eisenman éste recurrirá a los discursos de otras disciplinas para encontrar 
su camino, como la filosofía y la psicología, aunque también la geografía o la geología en algunos casos. Eisenman pone en diálogo los discursos de Derrida y Freud con las teorías del collage, pero también marcando algunas distancias con éste recurso pictórico.

A diferencia de Gehry o Libeskind, Eisenman utiliza fragmentos de planimetrías o cartografías, a través de los cuales revela partes de la historia del lugar articulándolas entre sí. Sus proyectos hacen posible el devenir de restos o ruinas pasada y ocultas, invisibles pero latentes en el lugar, y que el arquitecto como un hábil collagista o bricoleur facilita su reaparición en sus obras.

Los fragmentos utilizados por Eisenman tienen una relación directa con el lugar y el contexto donde se implantará el proyecto: son parte de su historia o elementos del lugar materializados en capas de representación gráfica; planimetrías o cartografía. Dichos segmentos luego se articulan entre sí como un puzle que permite re-construir la memoria del sitio. Tales datos, restos o ruinas, en ocasiones no están visibles en el solar; destrucciones bélicas, reconversiones edilicias o simplemente demoliciones han provocado sus ausencias materiales o vacíos espaciales que impiden tener presente el pasado del lugar. Para recuperar dichos fragmentos intangibles de la historia o la memoria del lugar, o los tangibles como restos y ruinas, Eisenman recurre a discursos extra disciplinares como la filosofía y la psicología, los cuales nutren y abonan los argumentos que dan sustento teórico a una serie de estrategias proyectuales conceptuales y operativas elaboradas para alcanzar los citados cometidos.

Para producir las estrategias conceptuales recurre a los discursos freudianos de huella, signo y señal o a los derrideanos de espectros, herencia o injerto, entre otros con los que fortalece sus planteamientos arquitectónicos. A partir de estas estrategias Eisenman obtiene selectivamente los datos del lugar, que luego traduce en información gráfica y/o escrita, la cual interrelaciona a partir de la puesta en

8. Peter Eisenman. Cannaregio Town Square \& Parque de La Villette. Elaboración propia, 2021.

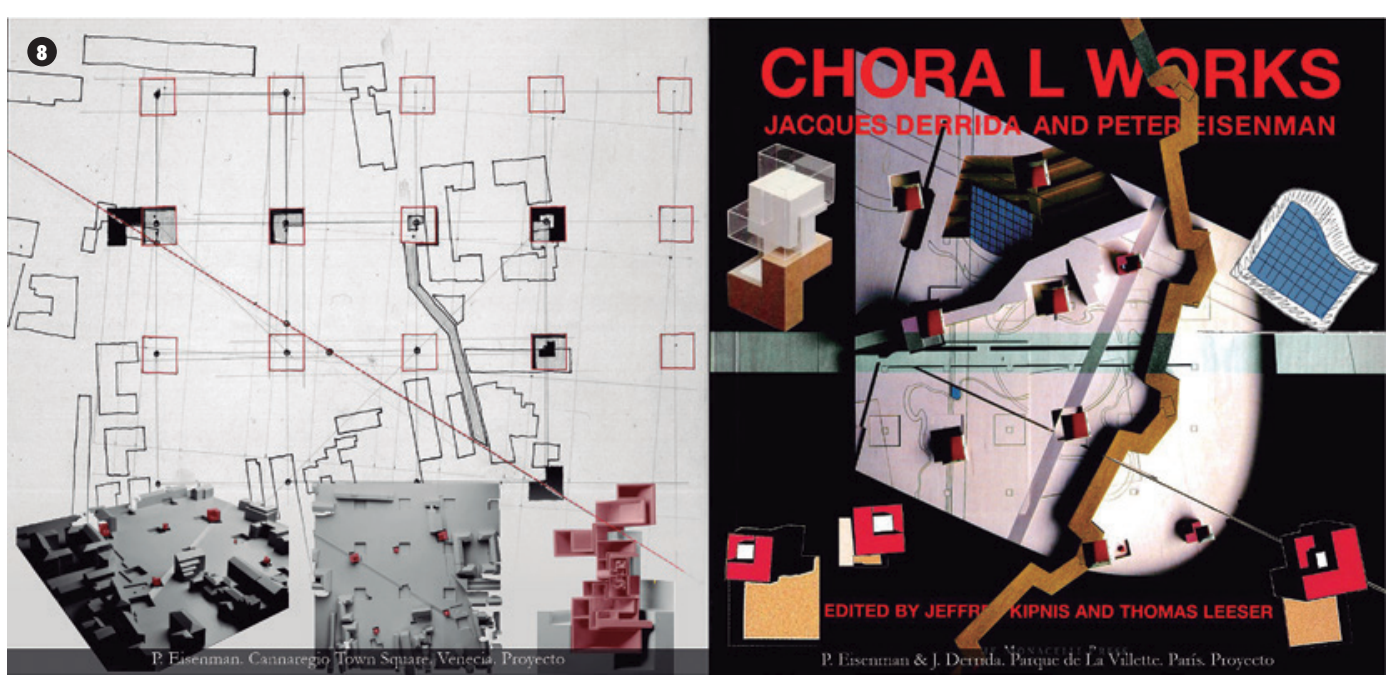

funcionamiento de las estrategias operativas de las que destacamos tres, por su relación con el asunto de estudio: Overlapping o superposición, Graft o injerto, Bleaching y Blurring o borrado / desdibujado / difuminado ${ }^{4}$.

Tales estrategias son las que pone en marcha durante el desarrollo de una serie de once proyectos urbano-arquitectónicos conocidos como Cities of Artificial Excavation o Ciudades de la arqueología ficticia, llevados a cabo en Europa y EE.UU. entre 1978 y 1989.

En su primer proyecto de la serie, Cannaregio Town Square de Venecia (1978), reúne restos de ruinas edilicias del veneciano barrio de San Giobbe, junto a fragmentos espectrales del proyecto para el hospital de Venecia de Le Corbusier de 1962, más una reelaborada interpretación de su proyecto para la House Xla, que injerta en este proyecto a modo de folies (Figura 8).

En su proyecto junto a Tschumi y Derrida para un Jardín no vegetal en el Parque de La Villette en París (1985) retoma algunos planteamientos desarrollados para Cannaregio, especialmente sus folies, las cuales dialogan con las diseñadas por Tschumi para su propuesta, constituyéndose ambas en embajadoras de buena voluntad entre los dos proyectos. Además de los planteamientos arquitectónicos, se solapan y articulan en dicho parque aportes provenientes del cine y la filosofía, especialmente los relativos a la teoría y la gráfica derrideana sobre Khôra. A todo ello se suman las recuperaciones cartográficas de la antigua muralla parisina de Thiers del siglo XIX, con el trazado contemporáneo del lugar y sus edificios existentes (FIGURA 8).

En el conjunto de viviendas de Berlín (1980) articula sobre la retícula de Mercator las huellas ficticias de la ciudad histórica del siglo XIX, con los restos de los tres únicos edificios existentes en la manzana, sobrevivientes bélicos, más las trazas espectrales del contiguo Muro de Berlín y del mítico Checkpoint Charlie que asedian al proyecto (FIGURA 9)

En su proyecto para los castillos de Romeo y Julieta en Verona (1985), confluyen fragmentos de datos arquitectónicos, históricos, geográficos y literarios. El proyecto pone en diálogo la ubicación y edificación de los imaginarios

\footnotetext{
4 La cuarta estrategia desarrollada por Eisenman es Scaling o escalado.
} 
castillos que la tradición asocia a las familias Montesco y Capuleto, con los lugares ficticios en los que se desarrollaron los principales episodios de la historia de Shakespeare, como la capilla nupcial de Romeo y Julieta o su tumba. Todo ello se articula con el trazado urbano actual de la ciudad de Verona, con la recuperación ficticia de los históricos cardo y decumano de la ciudad romana, las antiguas murallas medievales que rodean la ciudad y el relevante meandro del río Adige que divide la ciudad en dos sectores, enfatizando ideas de unión/división/relación dialéctica entre las partes y el todo (FIGURA 9).

En el Wexner Center for the Visual Arts en Ohio (1983), Eisenman reúne y solapa articuladamente la cuadrícula urbana de la ciudad de Columbus con el trazado urbano del campus, los cuales entrelaza con los edificios del hall y el auditórium ya existentes, con las nuevas construcciones y con la recuperación metafórica del antiguo edificio del arsenal, materializados como ruinas espectrales del lugar. Todo ello entrelazado en torno a la estructura espacial reticular que alberga los dos grandes corredores del conjunto y que ponen en diálogo los fragmentos de los demás elementos que se entrecruzan y solapan (Figura 10).

En el proyecto para el Museo de arte de la California State University en Long Beach (1986) Eisenman superpone mapas y planos que representan la historia geológica, geográfica y política de Long Beach. Relaciona imágenes cartográficas de los contornos del campus y del terreno del museo, la configuración del rancho sobre el que se fundó la ciudad, las modificaciones del territorio provocadas por la transformación del trazado del litoral y la canalización de los ríos, la trama catastral del territorio y el trazado de la línea de falla geológica Newport-Inglewood que atraviesa el lugar (FIGURA 10).

Como se observa, todos los proyectos de las Ciudades de la Arqueología Ficticia se constituyen a partir de imágenes que reaparecen yuxtapuestas de diferentes formas en el plano,

9. Peter Eisenman. Viviendas en Berlín \& Romeo y Julieta. Elaboración propia, 2021.

10. Peter Eisenman. Wexner Center \& Museo en Long Beach. Elaboración propia, 2021.
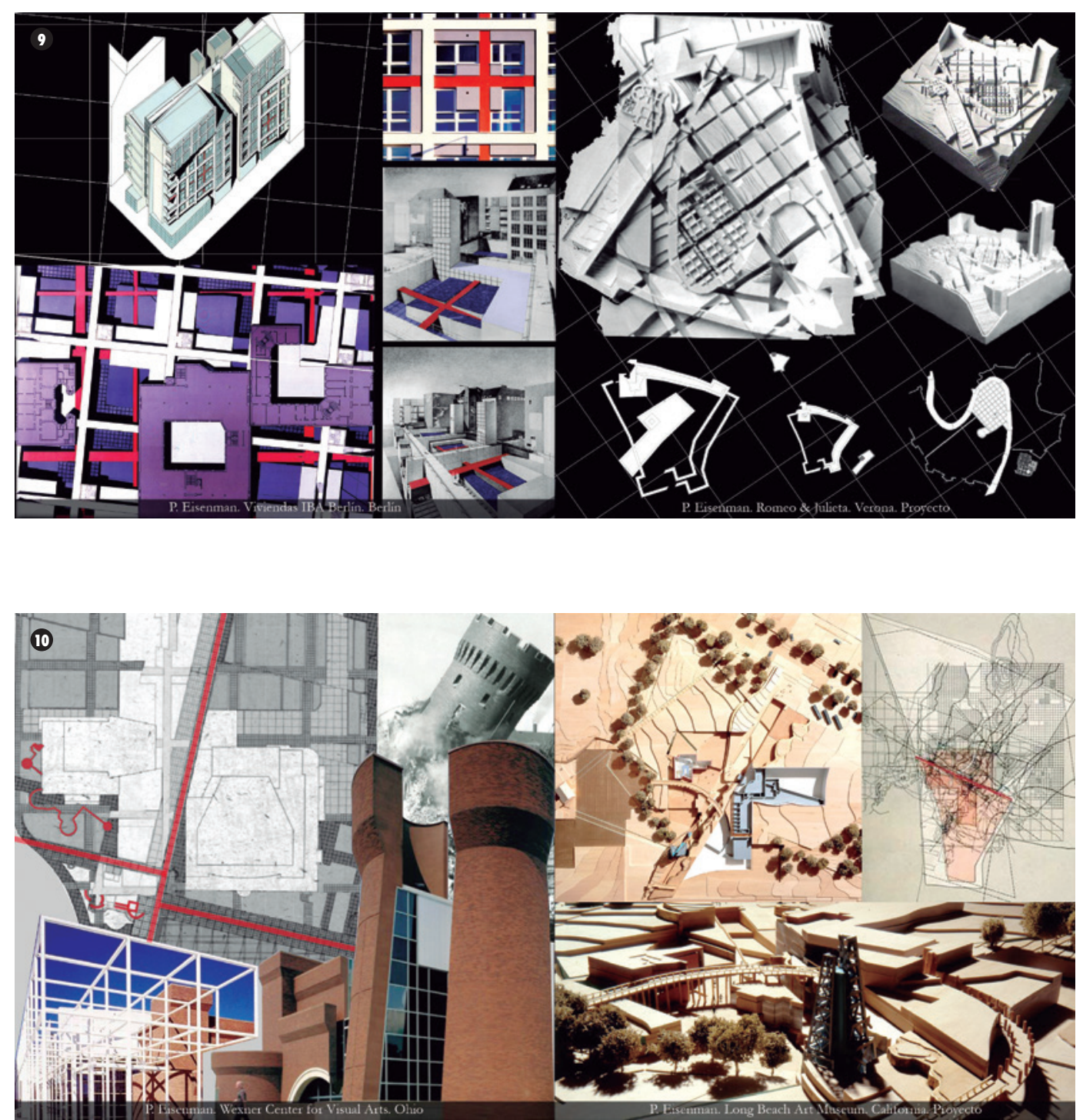

y durante toda la elaboración del proyecto, trabajadas como objetos arqueológicos que llevan las huellas de su pasado. A partir de los fragmentos superpuestos de elementos pretéritos, Eisenman elabora una propuesta donde pasado, presente y futuro se amalgaman y articulan en un overlapping proyectual, en un collage arquitectónico conspicuo.

Al igual que Gehry y Libeskind, Eisenman debe reunir los fragmentos identificados y seleccionados del lugar para finalizar su proyecto. Aquí y ahora es cuando pondrá en marcha plenamente las estrategias operativas antes señaladas: Overlapping, Graft, Bleaching o Blurring. De hecho, Philip Johnson y Mark Wigley, en el catálogo de la exposición del MoMA Arquitectura deconstructivista, habían destacado la superposición como recurso proyectual en las obras de los siete estudios de arquitectura reunidos en la muestra cuando sostenían: "Tomemos como ejemplo el más obvio de los temas formales que repiten cada uno de ellos: la superimposición en diagonal de 
formas rectangulares o trapezoidales" (Johnson, Wigley, 1988, p. 7).

A través del overlapping Eisenman reúne los fragmentos de información recuperados del lugar por medio de la excavación ficticia o palimpsesto, generando una serie de gráficas solapadas, articuladas y fluctuantes entre sí, las cuales producen una de las tantas imágenes emergente posibles del proyecto por venir, la cual con su representación evoca una instantánea de un proceso proyectual dinámico y latente permanentemente. $Y$ si bien Eisenman recurre a la superposición y expone cómo ésta forma parte de sus procesos proyectuales, marca ciertas distancias con técnicas similares empleadas en el collage. Para Eisenman el collage se caracteriza por la superimposición mientras que el overlapping anhela una superposición flexible de elementos, sin imposiciones y con un nivel de impredecibilidad que desestabiliza constantemente el proceso proyectual. Como él mismo sugiere, overlapping es "la existencia simultánea de dos o tres capas formales e históricas que producen un estado diferente de lugar, totalmente artificial (...) que no tiene nada que ver con lo que anteriormente se encontraba en el lugar (...) que sólo existe en la yuxtaposición" (Bédard, 1995, p. 38).

Finalmente, si fuera necesario Eisenman recurrirá al Graft para afianzar la consolidación de los fragmentos, injertando en el proyecto un dato o elemento nuevo, e incluso ficticio de ser requerido, en el afán de potenciar las imágenes emergentes por venir en el proyecto. Así lo expone Eisenman en su entrevista con Bédard (1995):

"Como ejemplo del origen artificial, podríamos tomar el injerto que es la inserción de un cuerpo extraño en un sujeto con el fin de producir un nuevo ejemplar. Al contrario de los elementos de un collage o de un montaje, que pertenecen a un contexto y suponen un origen, el injerto representa un lugar inventado, que no tiene más características que las del proceso de su creación. (...) Además, por su naturaleza artificial y relativa, el injerto no es necesariamente en sí un objeto realizable, sino simplemente un lugar que contiene una invitación a actuar -es decir, el comienzo de un proceso" (pp. 13-14).

Su planteamiento del Graft se emparenta con los realizados por Derrida para quien el injerto produce efectos diseminatorios, que impiden una producción e interpretación única de la obra, abriendo posibilidades de heterogeneidad proyectual e interpretativa cuando ésta se recepciona, frente a la reivindicada unidad $u$ homogeneidad de otras propuestas arquitectónicas tradicionales (Peretti, 1989, pp. 156-162).

El injerto afecta al contenido y a la forma. Al injertar, si bien ambas partes se deforman también se transforman, se contaminan en su contenido, pasando elípticamente de la una a la otra y por ende se benefician, extendiendo los límites de las producciones por venir y sus interpretaciones. Es decir, abre posibilidades diseminatorias, reenvíos incesantes, y multiplicidades de lecturas heterogéneas a la vez que desconcertantes ante la ausencia de una univocidad interpretativa de la obra. Frente al injerto el proceso de significación es siempre plural (Peretti, 1989, pp. 154-155).

Pero además de las estrategias conceptuales y operativas señaladas, los once proyectos de la serie Ciudades de la Arqueología Ficticia destacan en relación al collage porque en todos ellos Eisenman recurre explícitamente a dicha técnica para su representación gráfica. El catálogo de la muestra llevada a cabo en el Centro Canadiense de Arquitectura (Bédard, 1994) permite ver las planimetrías o cartografía presentadas por Eisenman en dicha oportunidad, en la cuales observamos recortes de planos históricos, cartografías técnicas, restos arquitectónicos existente en los sitios, como torres, murallas, puentes, etc., trazados de ríos, incluso trozos de textos, organizados en capas, a las cuales se incorporan otras, si fuera necesario, con representaciones abstractas de colores neutralizados, indefinidos, y en las que destacan algunas veladuras doradas. Estas fragmentadas capas de lugares, construcciones históricas, restos y ruinas, trazados urbanos, etc. se articulan entre sí por medio de una cuidada superposición de las mismas georreferenciadas espacialmente, lo cual permite vincular en el lugar preciso, y por qué no en el momento justo, todos los elementos recuperados del lugar, emergiendo a través de una suerte de Gateway arquitectónica, la nueva propuesta edilicia; una emanación de lo virtual hacia lo real.

\section{EL COLLAGE COMO PARERGON INHERENTE EN LAS ARQUITECTURAS DECONSTRUCTIVAS}

Esta presentación pretendía explorar las relaciones o influencias existentes entre las estrategias de fragmentación, superposición, macla o injerto empleadas por la técnica artística del collage y por las propuestas arquitectónicas deconstructivistas, a raíz de los numerosos escritos que al ocuparse de la deconstrucción la refieren comparativamente al collage.

El escrito permitió identificar dos líneas de estrategias proyectuales emergentes a partir de la técnica del collage, las que se pueden sintetizar entre las tensas maclas de volúmenes heteróclitos de Gehry o Libeskind y las dialécticas superposiciones de planimetrías históricas del lugar de Eisenman.

Pero fundamentalmente el trabajo permitió mostrar en qué medida algunas conceptualizaciones sobre el collage bien podrían emplearse para referir a la arquitectura deconstructivista. Entre ambos planteamientos hay ciertos paralelismos que exceden la coincidencia del origen francés de ambos términos. El collage es, al igual que la arquitectura deconstructivista, una propuesta abierta, susceptible a una multiplicidad de interpretaciones como consecuencia de la coexistencia de géneros heterogéneos con propiedades aparentemente contradictorias. Ambos cuestionan la noción de unidad, de 
entidad de la obra al introducir la idea de fragmentación, de dispersión. Las fronteras de los componentes son flexibles o extensibles, es decir, no hay límites precisos, estos están desdibujados. Collage y Deconstrucción se caracterizan por presentar colisiones, maclas y enfrentamientos de lenguajes, de elementos, de formas, de colores, de materiales; de construcciones físicas. Ambos trabajan exhaustivamente con los materiales, combinándolos y alterándolos.

Hasta tal punto ambas propuestas son abiertas y flexibles que acogen dialécticamente en su seno discursos de otras disciplinas como la mineralogía, psicología, filosofía, geología, geografía, historia, etc. las que aportan los nutrientes fundamentales para el desarrollo de las nóveles estrategias proyectuales arquitectónicas, desarrolladas a partir del diálogo collage-deconstrucción o si se prefiere arte-arquitectura. Es decir, en torno al punto de contacto que se produce entre collage y arquitectura giran otros discursos extra disciplinares que se espiralan centrípetamente sobre aquellos dos, nutriéndolos, y a su vez reverberando de forma impredecible en nuevas propuestas arquitectónicas inimaginables por venir.

\section{REFERENCIAS BIBLIOGRÁFICAS}

Bédard, J.-F. (1995). Ciudades de la Arqueología Ficticia: Obras de Peter Eisenman, 1978-1988. Madrid: Ministerio de Obras Públicas / Montreal: Canadian Center for Architecture.

Ching, F. (1998). Arquitectura: Forma, espacio y orden. México: Gustavo Gili.

Freitas Fuao, F. (1992). Arquitectura como collage. Barcelona: ETSAB/UPC. Tesis doctoral.

Gracia, F de. (1996). Construir en lo construido. La arquitectura como modificación. Madrid: Nerea.

Johnson, P. \& Wigley, M. (1988). Arquitectura deconstructivista. Barcelona: Gustavo Gili.

Leupen, B. et al. (1999). Proyecto y Análisis. Evolución de los principios en arquitectura. Barcelona: Gustavo Gili.

Linares García, F. (2018). Recorta y pega: Los primeros usos del collage y fotomontaje en la representación de la arquitectura moderna. Estoa, (13), p. 37-49. DOI: 10.18537/est.v007.n013. a03

López-Bahut, E. (2016). De los collages y maquetas de vidrio de Oteiza al hormigón de Sáenz de Oíza. VLC Arquitectura, 3 (1), p. 55-83. DOI: http:// dx.doi.org/10.4995/vlc.2016/4255

Lucan, J. (1988). Deconstruir la arquitectura. Arquitectura (270), pp. 18-23.
Lus Arana, L. (2017). Real Fictions. Collage, fotomanipulación, e imagen arquitectónica en la era digital. ZARCH, (9), pp. 106-121. http://dx.doi.org/10.26754/ojs_zarch/ zarch.201792270

Maderuelo, J. (1990). El espacio raptado. Interferencias entre Arquitectura y Escultura. Madrid: Mondadori.

Molina Rodríguez, S. de. (2014). Collage y Arquitectura. La forma intrusa en la construcción del proyecto moderno. Sevilla: Recolectores Urbanos.

Moneo, R. (1990). Permanencia de lo efímero. La construcción como arte trascendente. Monografías de Arquitectura y Vivienda, (25), pp. 9-12.

Peretti Peñaranda, C. de. (1989). Jacques Derrida. Texto y deconstrucción. Barcelona: Anthropos.

Ramírez, J.A. (1991). El arte de las vanguardias, Madrid: Anaya.

Rowe, C. / Koetter, F. (1981). Ciudad Collage. Barcelona: Gustavo Gili.

Soriano, F. (1996). Hacia una definición de la planta profunda, de la planta anamórfica y de la planta fluctuante. El croquis, (81/82), p. 4-13.

Tschumi, B. (1988). Locura y combinatoria. Arquitectura, (270), pp. 26-32.

Zaera-Polo, A. (1995). Conversaciones con Frank Gehry. El Croquis, (74/75), pp. 6-37. 